\title{
Development of RSM Model in Surface Modification of EN-31 Die Steel Material Using Copper-Tungsten Powder Metallurgy Semi-Sintered Electrodes by EDM Process
}

\author{
H. S. Sidhu, ${ }^{1, *}$, S. S. Banwait ${ }^{2}$, S. C. Laroiya ${ }^{2}$ \\ ${ }^{1}$ Department of Mechanical Engineering, SBAS Government Polytechnic College, Badbar, India \\ ${ }^{2}$ Department of Mechanical Engineering, National Institute of Technical Teachers Training and Research, Chandigarh, India \\ *Corresponding author: hss1636@gmail.com
}

Received November 06, 2013; Revised November 20, 2013; Accepted November 29, 2013

\begin{abstract}
Electrical discharge machining is a well-established non-traditional machining process and it has been used extensively in tool and die making industry to machine complicated contours in electrically conductive hard materials. Surface modification by using metal powder mixed in dielectric fluid or by using reverse polarity semisintered/sintered powder metallurgy tool electrode is an uncommon aspect of electrical discharge machining process. In present work attempts have been made to model the surface modification phenomenon by electrical discharge machining process with response surface methodology technique. Two output response parameters, surface deposition rate and surface roughness has been correlated with four input variables, peak discharge current, pulse-on time, pulse-off time, powder compaction pressure and results obtained have been discussed. Design of experiment techniques, response surface methodology and analysis of variance were carried out to model the pertinent process parameters. The average prediction errors of the developed models confirms very well with the experimental values.
\end{abstract}

Keywords: electrical discharge machining, response surface methodology, design of experiments, analysis of variance, surface deposition rate, surface roughness

Cite This Article: H. S. Sidhu, S. S. Banwait, and S. C. Laroiya, "Development of RSM Model in Surface Modification of EN-31 Die Steel Material Using Copper-Tungsten Powder Metallurgy Semi-Sintered Electrodes by EDM Process.” American Journal of Mechanical Engineering 1, no. 6 (2013): 155-160. doi: 10.12691/ajme-16-2.

\section{Introduction}

Primarily electrical discharge machining (EDM) is a material removal process by controlled erosion through a series of electrical sparks between the tool electrode and the work-piece surface. The intense heat, generated in the sparking zone, causes the material to melt and evaporate locally, resulted as a material removal process. The unique feature of EDM is the utilization of its thermal energy to machine electrically conductive parts regardless of its hardness, has become its distinctive advantage in the field of manufacturing dies, moulds, aerospace, surgical and automotive components [1].

During investigations in to the electrical discharge machining of hardened tool steel using different electrode materials, Singh et at. [2] found that the re-solidified layer is actually an alloy composed both of electrode material and decomposed products of dielectric like carbon. The phenomenon of surface modification has been observed in the EDM process for more than four decades ago. As earlier in 1965, Barash and Kahlon [3] has found a very hard layer which was very difficult to remove by filing, coated on the surface of work-piece during EDM process of mild steel using copper tool electrode in paraffin dielectric medium. This was due to the carburization of the layer in presence of hydrocarbon medium and its subsequent quenching. The material transfer was found to be a function of the various electrical parameters of the EDM process, chemical compositions of work-piece material, tool electrode and as well as the dielectric used.

Venkatesh and Parasnis [4] has achieved high surface hardness, excellent thermal stability, better wear resistance of the white layer and its phase transformation in their study of surface transformation in high speed steel after electro discharge machining. Reverse polarity arrangement (negative tool electrode) is universally recommended for achieving surface modification by EDM process using powder-mixed dielectric.

Koshy et al. [5] has used the $\mathrm{Ni}, \mathrm{Co}, \mathrm{Fe}, \mathrm{Al}, \mathrm{Cr}, \mathrm{Cu}, \mathrm{Ti}$, $\mathrm{C}$ (graphite), Si and Mo metal powders with grain sizes between 1 and $100 \mu \mathrm{m}$ in dielectric medium during experimentation work on hardening of surface layers using electric discharge techniques and came out with conclusion that the addition of doping elements to the dielectric medium could be used to impart desired properties to the surface layer of the work-piece. It is due 
the presence of carbon in the hydrocarbon dielectric medium, which dissociates and combines with the doping elements to form their respective carbides.

Furutani et al. [6] has obtained titanium carbide layer of hardness $1600 \mathrm{HV}$ on carbon steel work-piece by adding titanium powder in kerosene dielectric with negative polarity copper tool electrode and choosing specific machine settings at $3 \mathrm{~A}$ peak current and $2 \mu \mathrm{sec}$ pulse duration for accretion of titanium carbide by electrical discharge machining with powder suspended in working fluid. The electrode used was rotating disk type which maintains the high powder concentration within the machining area.

During spark eroding of titanium work-piece by copper electrode along with urea added distilled water as a dielectric medium, Yan et al. [7] has obtained TiN on the surface of the work-piece, consequently resulted in improved friction and wear characteristics. Sharif and Noordin [8] carried out electrical discharge machining process of titanium work piece by adding $\mathrm{SiC}$ powder in dielectric medium and established an empirical model by using response surface methodology. The input variables, peak current, gap voltage and pulse-on time shows greater influence on material removal rate (MRR), tool wear rate (TWR) and surface roughness (SR). Further on the concentration of $\mathrm{SiC}$ mixed in dielectric has highest influence on surface roughness.

Kansal et al. [9] optimized the process parameters of powder mixed EDM process in terms of peak current, pulse-on time, duty cycle and concentration of SiC powder mixed into the dielectric medium as input variables with the usage of genetic algorithm based on neural network. The conclusions were that high peak current along with high powder concentration yields higher MRR and lower surface roughness.

Soni and Chakraverti [10] found the re-solidified layer which contains alloyed elements mostly migrated from both, tool electrode as well as work-piece. The surface integrity of the machined surface changes due to the presence of re-solidified alloyed materials on surface as well as in the heat affected zone. This phenomenon can be turned into an innovative and fairy cost effective technique for the modification of surface properties. Furthermore, it has inspired the researchers to operate the work-piece surface for intentionally transfer of tool material over it by EDM process using sintered/semisintered P/M compact electrode as machine tool. The prominent researches reported on surface modification by P/M compact EDM tools are as follows:

Recently powder metallurgy turns out to be a viable alternative to produce tool electrode with the desirable properties of different materials that can be combined. Moreover, the thermal, electrical, mechanical and microstructural properties of P/M electrodes can be effectively controlled by the process variables such as compacting pressure and sintering temperature. Thus the $\mathrm{P} / \mathrm{M}$ electrodes have a significant role in metal removal process in addition to their contribution in surface treatment application. Several researchers has studied surface modification after using $\mathrm{P} / \mathrm{M}$ green compact electrodes with EDM process, findings that the electrode element could be transferred to the machined surface to improve the mechanical properties [11].
EDM has established itself as one of the most commonly used and widely accepted non-traditional machining technique in the tool and die industry. However, the possibility of using EDM to modify the work surface was explored in recent time. The major disadvantage of nonconventional method of EDM is the formation of brittle and cracked recast layer on the machined surface. Since EDM is an isothermal process, so some alterations in surface integrity take place due to the formation of recast white layer. The phenomenon of surface modification by EDM process has enough scope to be explored. There are very few applications of response surface methodology in this process. In the present work RSM has been applied to model the surface modification phenomenon of EN-31 die steel work material by EDM process with copper-tungsten $(\mathrm{Cu}-\mathrm{W})$ semi-sintered P/M electrode.

\section{Experimentation}

Die sinking EDM machine (model: A25 spark generator integrated type, make: Toolcraft India) was used for experimentation work. The machine can run either in normal polarity or in reverse polarity, but reverse polarity has been used for present experimentation work. Semi sintered P/M tool electrodes made up from 8\% copper and $92 \%$ tungsten powders by weight percentage was formed at different compaction pressure for deliberate transfer of electrode material over EN-31 die steel work piece surface. This has resulted in deposition of a hard and composite material layer on work piece surface, thereby changing its surface integrity. In the present study, surface deposition rate (SDR) and surface roughness (SR) have been considered for evaluating the machining performance. These performance characteristics are correlated with input machining parameters such as peak current $\left(\mathrm{I}_{\mathrm{p}}\right)$, pulse-on time $\left(\mathrm{T}_{\text {on }}\right)$, pulse-off time $\left(\mathrm{T}_{\text {off }}\right)$ and powder compaction pressure $\left(\mathrm{P}_{\mathrm{c}}\right)$.

The work piece material used in these experiments was EN-31 steel having dimensions of $30 \times 15 \times 6 \mathrm{~mm}$. The selection of this material was made by taking in to account its extensive use in tool and die industry. Chemical composition of work material is shown in Table 1. During machining, EDM oil (EDM-30) was used as dielectric fluid with side flushing technique. The machining times for all experiments were kept constant at 3 minutes.

Table 1. Chemical composition of EN-31 steel (wt.\%)

\begin{tabular}{|c|c|c|c|c|c|c|c|}
\hline Elements & C & Si & Mn & P & S & Cr & Fe \\
\hline Wt. \% & 1.3 & 03 & 0.5 & 0.024 & 0.025 & 1.4 & Balance \\
\hline
\end{tabular}

Table 2. Machining conditions used during experimentation work

\begin{tabular}{|l|l|}
\hline \multicolumn{1}{|c|}{ Working Conditions } & \multicolumn{1}{c|}{ Description } \\
\hline Work piece material & AISI EN-31die steel \\
\hline Electrode composition & $8 \% \mathrm{Cu}-92 \% \mathrm{~W}$ \\
\hline Sintering Temperature & $300^{\circ} \mathrm{C}$ \\
\hline Compaction Pressure & $900-1300 \mathrm{Mpa}$ \\
\hline Peak current & $3-9 \mathrm{~A}$ \\
\hline Pulse-on time & $5-25 \mu \mathrm{sec}$ \\
\hline Pulse-off time & $50-250 \mu \mathrm{sec}$ \\
\hline Polarity & Negative \\
\hline Dielectric fluid & EDM-30 \\
\hline Dielectric flushing & Side flushing \\
\hline Processing time & 3 min \\
\hline
\end{tabular}


The process parameters, output measures and machining conditions used during experimentation are listed in Table 2. These were chosen through literature survey, reviews of experience, and some preliminary investigations. Moreover, some pilot experiments were conducted to fix the levels among the available options.

The work-piece was cleaned with acetone before and after each experiment and then dried with a dryer and precisely weighed. A digital balance (make: Essae Teraoka) with $0.1 \mathrm{mg}$ resolution was used to calculate the SDR. The centreline average value $\left(R_{a}\right)$ for $S R$ was measured by portable roughness tester 'Surftest SJ-301' (make: Mitutoyo) . The cut-off length was set at $2.5 \mathrm{~mm}$ with an evaluation length of $10 \mathrm{~mm}$.The average value of six SR measurements was recorded in different directions for each specimen and these values has been used for development of SR model. The surface roughness (Ra) value of the work surface has been obtained in the wide range of 5.079 to $7.804 \mu \mathrm{m}$.

\subsection{Design of Experiments}

A central composite design with five levels for each independent variable was used for planning the experimentation work. The design initially chosen was factorial design $2^{4}$ with 6 central point's which provides the information about curvature existence, consequently carrying out a total number of 22 experiments. The addition of six central points was allowed to carry out lack-of-fit test for the proposed first order model. In case first order model fails to reveal the behaviour of response that was studied, then it was further widened by addition of eight axial runs located on each axis at two alpha levels. So in case of second order CCD model a total of 30 experiments were carried out. Based on CCD, experiments were conducted to develop mathematical model for SDR and SR in terms of four input parameters; peak current, pulse-on time, pulse-off time and powder compaction pressure. Each input parameter had five levels of variation $( \pm 2, \pm 1,0)$.

The input process parameters along with their levels, used in experimentation are listed in Table 3. The range of input parameters, i.e. peak current $\left(\mathrm{I}_{\mathrm{p}}\right)$, pulse-on time $\left(\mathrm{T}_{\mathrm{on}}\right)$, pulse-off time $\left(\mathrm{T}_{\text {off }}\right)$ and powder compaction pressure $\left(\mathrm{P}_{\mathrm{c}}\right)$ was selected after performing a number of pilot experiments.

Table 3. Experimental input variables along with selected levels

\begin{tabular}{|l|c|c|c|c|c|c|}
\hline Process Parameters & Units & \multicolumn{6}{|c|}{ Levels } \\
\cline { 3 - 7 } & & -2 & -1 & 0 & +1 & +2 \\
\hline Peak current & $\mathrm{A}$ & 3 & 4.5 & 6 & 7.5 & 9 \\
\hline Pulse on time & $\mu \mathrm{s}$ & 5 & 10 & 15 & 20 & 25 \\
\hline Pulse off time & $\mu \mathrm{s}$ & 50 & 100 & 150 & 200 & 250 \\
\hline Compaction pressure & $\mathrm{MPa}$ & 900 & 1000 & 1100 & 1200 & 1300 \\
\hline
\end{tabular}

Table 4 contains the design of experiment (DOE) matrix having actual and coded values of the input variables along with two output responses.

Table 4. Design of Experiment matrix and machining characteristics

\begin{tabular}{|c|c|c|c|c|c|c|c|c|c|c|}
\hline \multirow[t]{3}{*}{ Exp. No. } & \multicolumn{8}{|c|}{ Input process parameters } & \multicolumn{2}{|c|}{ Observed responses } \\
\hline & \multicolumn{2}{|c|}{$\mathrm{I}_{\mathrm{p}}$} & \multicolumn{2}{|c|}{$\mathrm{T}_{\mathrm{on}}$} & \multicolumn{2}{|c|}{$\mathrm{T}_{\text {off }}$} & \multicolumn{2}{|c|}{$\mathrm{P}_{\mathrm{c}}$} & \multirow{2}{*}{$\begin{array}{c}\text { SDR } \\
(\mathrm{mg} / \mathrm{min})\end{array}$} & \multirow{2}{*}{$\begin{array}{c}\text { SR } \\
(\mu \mathrm{m})\end{array}$} \\
\hline & Actual & Coded & Actual & Coded & Actual & Coded & Actual & Coded & & \\
\hline 1 & 4.5 & -1 & 10 & -1 & 100 & -1 & 1000 & -1 & 30.83 & 7.361 \\
\hline 2 & 7.5 & 1 & 10 & -1 & 100 & -1 & 1000 & -1 & 45.03 & 6.202 \\
\hline 3 & 4.5 & -1 & 20 & 1 & 100 & -1 & 1000 & -1 & 34.90 & 7.804 \\
\hline 4 & 7.5 & 1 & 20 & 1 & 100 & -1 & 1000 & -1 & 45.53 & 6.251 \\
\hline 5 & 4.5 & -1 & 10 & -1 & 200 & 1 & 1000 & -1 & 16.80 & 5.658 \\
\hline 6 & 7.5 & 1 & 10 & -1 & 200 & 1 & 1000 & -1 & 25.03 & 5.310 \\
\hline 7 & 4.5 & -1 & 20 & 1 & 200 & 1 & 1000 & -1 & 18.33 & 6.100 \\
\hline 8 & 7.5 & 1 & 20 & 1 & 200 & 1 & 1000 & -1 & 26.93 & 5.367 \\
\hline 9 & 4.5 & -1 & 10 & -1 & 100 & -1 & 1200 & 1 & 27.80 & 6.263 \\
\hline 10 & 7.5 & 1 & 10 & -1 & 100 & -1 & 1200 & 1 & 42.50 & 5.722 \\
\hline 11 & 4.5 & -1 & 20 & 1 & 100 & -1 & 1200 & 1 & 30.70 & 6.972 \\
\hline 12 & 7.5 & 1 & 20 & 1 & 100 & -1 & 1200 & 1 & 42.67 & 6.097 \\
\hline 13 & 4.5 & -1 & 10 & -1 & 200 & 1 & 1200 & 1 & 14.67 & 5.313 \\
\hline 14 & 7.5 & 1 & 10 & -1 & 200 & 1 & 1200 & 1 & 23.50 & 5.533 \\
\hline 15 & 4.5 & -1 & 20 & 1 & 200 & 1 & 1200 & 1 & 15.47 & 6.008 \\
\hline 16 & 7.5 & 1 & 20 & 1 & 200 & 1 & 1200 & 1 & 24.10 & 5.858 \\
\hline 17 & 3.0 & -2 & 15 & 0 & 150 & 0 & 1100 & 0 & 17.90 & $\begin{array}{l}6.998 \\
\end{array}$ \\
\hline 18 & 9.0 & 2 & 15 & 0 & 150 & 0 & 1100 & 0 & 38.63 & 5.635 \\
\hline 19 & 6.0 & 0 & 5 & -2 & 150 & 0 & 1100 & 0 & 29.10 & 5.563 \\
\hline 20 & 6.0 & 0 & 25 & 2 & 150 & 0 & 1100 & 0 & 32.33 & 6.393 \\
\hline 21 & 6.0 & 0 & 15 & 0 & 50 & -2 & 1100 & 0 & 50.20 & 6.897 \\
\hline 22 & 6.0 & 0 & 15 & 0 & 250 & 2 & 1100 & 0 & 16.63 & 5.079 \\
\hline 23 & 6.0 & 0 & 15 & 0 & 150 & 0 & 900 & -2 & 31.67 & 6.462 \\
\hline 24 & 6.0 & 0 & 15 & 0 & 150 & 0 & 1300 & 2 & 26.57 & 5.793 \\
\hline 25 & 6.0 & 0 & 15 & 0 & 150 & 0 & 1100 & 0 & 34.17 & 6.033 \\
\hline 26 & 6.0 & 0 & 15 & 0 & 150 & 0 & 1100 & 0 & 33.80 & 6.059 \\
\hline 27 & 6.0 & 0 & 15 & 0 & 150 & 0 & 1100 & 0 & 33.90 & 6.107 \\
\hline 28 & 6.0 & 0 & 15 & 0 & 150 & 0 & 1100 & 0 & 33.83 & 6.020 \\
\hline 29 & 6.0 & 0 & 15 & 0 & 150 & 0 & 1100 & 0 & 33.78 & 6.044 \\
\hline 30 & 6.0 & 0 & 15 & 0 & 150 & 0 & 1100 & 0 & 33.80 & 6.120 \\
\hline
\end{tabular}

\subsection{Mathematical Modelling with RSM}

Response Surface methodology is an interaction of mathematical and statistical techniques that are useful for developing, analysing, improving and optimizing the processes [12]. In the present work, by the use of DOE and applying regression analysis, surface deposition rate and surface roughness prediction model with independent input variable has been obtained. If all variables are assumed to be measurable, the first order model can be written as; 


$$
\hat{\mathrm{Y}}=\mathrm{Y}-\varepsilon=\mathrm{b} 0+\mathrm{b} 1 \mathrm{I}_{\mathrm{p}}+\mathrm{b} 2 \mathrm{~T}_{\mathrm{on}}+\mathrm{b} 3 \mathrm{~T}_{\text {off }}+\mathrm{b} 4 \mathrm{P}_{\mathrm{c}}
$$

$\hat{\mathrm{Y}}$ is the response function (or response surface) and $\mathrm{Y}$ is the measured value of corresponding response functions SDR and SR. The model coefficients, b0, b1, b2, b3, b4 are to be estimated and where $\varepsilon$ is the fitting error of the experimental observations. In this study, four variables (i.e., $\mathrm{I}_{\mathrm{p}}, \mathrm{T}_{\mathrm{on}}, \mathrm{T}_{\text {off }}, \mathrm{P}_{\mathrm{c}}$ ) are under consideration. A second order polynomial regression model has been proposed as follows;

$$
\begin{aligned}
\hat{\mathrm{Y}}=\mathrm{Y}- & \varepsilon=\mathrm{b} 0+\mathrm{b} 1 \mathrm{I}_{\mathrm{p}}+\mathrm{b} 2 \mathrm{~T}_{\text {on }}+\mathrm{b} 3 \mathrm{~T}_{\text {off }}+\mathrm{b} 4 \mathrm{P}_{\mathrm{c}} \\
& +\mathrm{b} 5 \mathrm{I}_{\mathrm{p}} \mathrm{T}_{\text {on }}+\mathrm{b} 6 \mathrm{I}_{\mathrm{p}} \mathrm{T}_{\text {off }}+\mathrm{b} 7 \mathrm{I}_{\mathrm{p}} \mathrm{P}_{\mathrm{c}}+\mathrm{b} 8 \mathrm{~T}_{\text {on }} \mathrm{T}_{\text {off }} \\
& +\mathrm{b} 9 \mathrm{~T}_{\text {on }} \mathrm{P}_{\mathrm{c}}+\mathrm{b} 10 \mathrm{~T}_{\text {off }} \mathrm{P}_{\mathrm{c}}+\mathrm{b} 11 \mathrm{I}_{\mathrm{p}}{ }^{2}+\mathrm{b} 12 \mathrm{~T}_{\text {on }}{ }^{2} \\
& +\mathrm{b} 13 \mathrm{~T}_{\text {off }}{ }^{2}+\mathrm{b} 14 \mathrm{P}_{\mathrm{c}}{ }^{2}
\end{aligned}
$$

The adequacy for the model was checked by using the analysis of variance (ANOVA) technique.

\subsection{Modelling of SDR by RSM}

A second order model was created for mapping four input parameters, such as $\mathrm{I}_{\mathrm{p}}, \mathrm{T}_{\mathrm{on}}, \mathrm{T}_{\text {off }}$ and $\mathrm{P}_{\mathrm{c}}$ with single output parameter, SDR. The ANOVA and Fisher's statistical test was used to check the adequacy of the model as well as significance of each independent input variable. Table 5 shows ANOVA results of the proposed model for SDR. The ANOVA table contains sum of squares (SS), degree of freedom (df), mean squares (MS), F-value and P-value, where MS was obtained by dividing the SS of each of the sources of variation by the respective degree of freedom df. The F-value is the ratio of MS of the model terms to the MS of the residual, whereas the

\begin{tabular}{|c|c|c|c|c|c|}
\hline Source & SS & $\mathrm{df}$ & MS & F-Value & $\begin{array}{l}\text { P-value } \\
\text { Prob > F }\end{array}$ \\
\hline Model & 2583.81 & 14 & 184.56 & 219.16 & $<0.0001^{*}$ \\
\hline $\mathrm{I}_{\mathrm{p}}$ & 674.69 & 1 & 674.69 & 801.20 & $<0.0001^{*}$ \\
\hline $\mathrm{T}_{\text {on }}$ & 14.93 & 1 & 14.93 & 17.73 & $0.0008^{*}$ \\
\hline $\mathrm{T}_{\text {off }}$ & 1704.71 & 1 & 1704.71 & 2024.37 & $<0.0001^{*}$ \\
\hline $\mathrm{P}_{\mathrm{c}}$ & 43.12 & 1 & 43.12 & 51.21 & $<0.0001^{*}$ \\
\hline $\mathrm{I}_{\mathrm{p}} \mathrm{T}_{\text {on }}$ & 2.35 & 1 & 2.35 & 2.79 & 0.1156 \\
\hline $\mathrm{I}_{\mathrm{p}} \mathrm{T}_{\text {off }}$ & 18.51 & 1 & 18.51 & 21.98 & $0.0003^{*}$ \\
\hline $\mathrm{I}_{\mathrm{p}} \mathrm{P}_{\mathrm{c}}$ & 0.38 & 1 & 0.38 & 0.45 & 0.5112 \\
\hline $\mathrm{T}_{\text {on }} \mathrm{T}_{\text {off }}$ & 0.49 & 1 & 0.49 & 0.59 & 0.4558 \\
\hline $\mathrm{T}_{\text {on }} \mathrm{P}_{\mathrm{c}}$ & 0.78 & 1 & 0.78 & 0.92 & 0.3515 \\
\hline $\mathrm{T}_{\text {off }} \mathrm{P}_{\mathrm{c}}$ & 0.67 & 1 & 0.67 & 0.79 & 0.3871 \\
\hline $\mathrm{I}_{\mathrm{p}}^{2}$ & 72.46 & 1 & 72.46 & 86.04 & $<0.0001^{*}$ \\
\hline $\mathrm{T}_{\text {on }}{ }^{2}$ & 28.14 & 1 & 28.14 & 33.41 & $<0.0001^{*}$ \\
\hline $\mathrm{T}_{\text {off }}^{2}$ & 3.13 & 1 & 3.13 & 3.72 & 0.0730 \\
\hline $\mathrm{P}_{\mathrm{c}}^{2}$ & 54.65 & 1 & 54.65 & 64.90 & $<0.0001^{*}$ \\
\hline Residual & 12.63 & 15 & 0.84 & & \\
\hline Lack of Fit & 12.52 & 10 & 1.25 & 57.02 & 0.0002 \\
\hline Pure Error & 0.11 & 5 & 0.022 & & \\
\hline Cor Total & 2596.44 & 29 & & & \\
\hline R-Squared & & & & & 0.9951 \\
\hline Adj R-Squared & & & & & 0.9906 \\
\hline Pred R-Squared & & & & & 0.9722 \\
\hline Adeq Precision & & & & & 53.342 \\
\hline
\end{tabular}
residual is the difference between actual and predicted value. The P-value is the smallest level of significance at which the data is significance.

Table 5. ANOVA for SDR

SS: sum of squares, df: degree of freedom, MS: mean squares,

$(*)$ : Significant terms
The model F-value of 219.16 implies the model is significant. There is only a $0.01 \%$ chance that a "Model FValue" this large could occur due to noise. Values of "Prob > F" less than 0.0500, indicates, that model terms are significant. In this case $\mathrm{I}_{\mathrm{p}}, \mathrm{T}_{\mathrm{on}}, \mathrm{T}_{\text {off }}, \mathrm{P}_{\mathrm{c}}, \mathrm{I}_{\mathrm{p}} \mathrm{T}_{\text {off }}, \mathrm{I}_{\mathrm{p}}{ }^{2}, \mathrm{~T}_{\text {on }}{ }^{2}$, $\mathrm{P}_{\mathrm{c}}{ }^{2}$ are significant model terms. Values greater than 0.1000 indicate that the model terms are not significant. The "Lack of Fit F-value" of 57.02 implies the Lack of Fit is significant. There is only a $0.02 \%$ chance, that a "Lack of Fit F-value" this large could occur due to noise. The "Pred R-Squared" of 0.9722 is in reasonable agreement with the "Adj R-Squared" of 0.9906. "Adeq Precision" measures the signal to noise ratio. A ratio greater than 4 is desirable. The ratio of 53.342 indicates an adequate signal. From the above analysis and after eliminating the nonsignificance terms, the final equation for SDR is:

$$
\begin{aligned}
\mathrm{SDR}= & +33.88+5.30 \mathrm{I}_{\mathrm{p}}+0.79 \mathrm{~T}_{\text {on }}-8.43 \mathrm{~T}_{\text {off }} \\
& -1.34 \mathrm{P}_{\mathrm{C}}-1.08 \mathrm{I}_{\mathrm{p}} \mathrm{T}_{\text {off }}-1.63 \mathrm{I}_{\mathrm{p}}{ }^{2}-1.01 \mathrm{~T}_{\text {on }}{ }^{2}-1.41 \mathrm{P}_{\mathrm{C}}{ }^{2}
\end{aligned}
$$

Experimental values and predicted values by above equation was plotted in Figure 1. Plot and ANOVA reveals that model and Eq. (3) were highly significant and adequate to represent the actual relationship between input variables and output response. Furthermore the residuals V/s normal plots for SDR obtained shown in Figure 2. Normal distribution of residuals depicts data spread, that was approximately along a straight line, which show a good correlation between experimental and predicted values. As a whole analysis of a normal plot of residuals for SDR confirms the adequacy and prediction capability of the model.

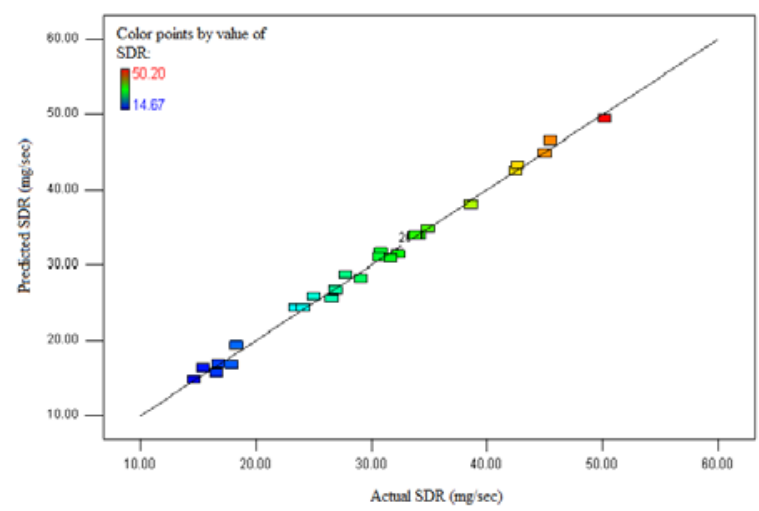

Figure 1. Variation of actual V/s predicted response for SDR

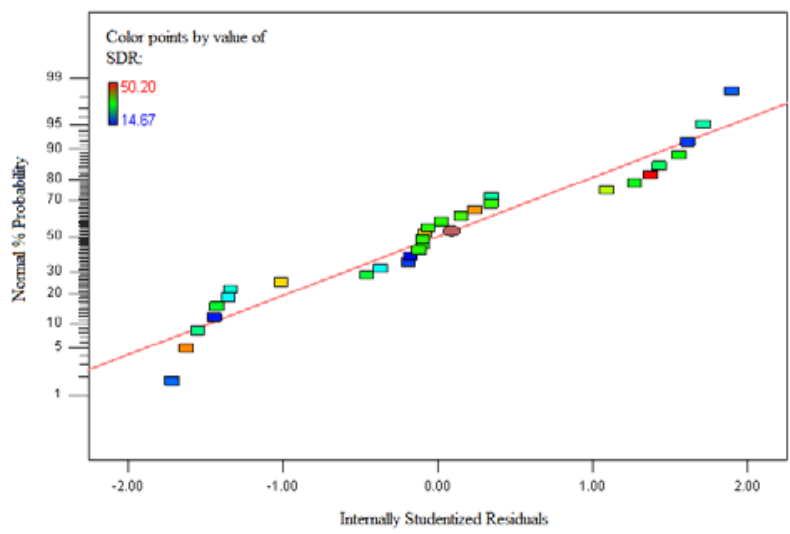

Figure 2. Normal plot of residuals for SDR 


\subsection{Mathematical Modelling with SR}

A second order model for SR was developed to correlate input variables, $I_{p}, T_{o n}, T_{\text {off }}$ and $P_{c}$ with one output parameter i.e., surface roughness (SR). Table 6 shows the ANOVA results for proposed model and significant model terms.

F-value of 640.09 implies that the model is significant. Values of "Prob $>$ F" less than 0.0500 indicate that model terms $\mathrm{I}_{\mathrm{p}}, \mathrm{T}_{\text {on }}, \mathrm{T}_{\text {off }}, \mathrm{P}_{\mathrm{c}}, \mathrm{I}_{\mathrm{p}} \mathrm{T}_{\text {on }}, \mathrm{I}_{\mathrm{p}} \mathrm{T}_{\text {off }}, \mathrm{I}_{\mathrm{p}} \mathrm{P}_{\mathrm{c}}, \mathrm{T}_{\text {on }} \mathrm{P}_{\mathrm{c}}, \mathrm{T}_{\text {off }} \mathrm{P}_{\mathrm{c}}, \mathrm{I}_{\mathrm{p}}{ }^{2}$, $\mathrm{T}_{\text {on }}{ }^{2}, \mathrm{~T}_{\text {off }}{ }^{2}, \mathrm{P}_{\mathrm{c}}{ }^{2}$ are significant. The "Pred R-Squared" of 0.9936 is in reasonable agreement with the "Adj RSquared" of 0.9968. "Adeq Precision" of 109.946 indicate an adequate signal. ANOVA analysis reveals that Eq. (4) was highly significant that can be used to navigate the design space. Final equation in terms of coded factors is as follows:

$$
\begin{aligned}
\mathrm{SR}= & +6.06-0.33 \mathrm{I}_{\mathrm{p}}+0.20 \mathrm{~T}_{\text {on }}-0.46 \mathrm{~T}_{\text {off }}-0.15 \mathrm{P}_{\mathrm{c}} \\
& -0.093 \mathrm{I}_{\mathrm{p}} \mathrm{T}_{\text {on }}+0.19 \mathrm{I}_{\mathrm{p}} \mathrm{T}_{\text {off }}+0.15 \mathrm{I}_{\mathrm{p}} \mathrm{P}_{\mathrm{c}}+0.070 \mathrm{~T}_{\text {on }} \mathrm{P}_{\mathrm{c}} \\
& +0.18 \mathrm{~T}_{\text {off }} \mathrm{P}_{\mathrm{c}}+0.065 \mathrm{I}_{\mathrm{p}}{ }^{2}-0.020 \mathrm{~T}_{\text {on }}{ }^{2}-0.017 \mathrm{~T}_{\text {off }}{ }^{2} \\
& +0.018 \mathrm{P}_{\mathrm{c}}^{2}
\end{aligned}
$$

\begin{tabular}{|c|c|c|c|c|c|}
\hline Source & SS & df & MS & F-Value & $\begin{array}{c}\text { P-value } \\
\text { Prob > F }\end{array}$ \\
\hline Model & 11.12 & 14 & 0.79 & 640.09 & $<0.0001^{*}$ \\
\hline $\mathrm{I}_{\mathrm{p}}$ & 2.58 & 1 & 2.58 & 2078.57 & $<0.0001^{*}$ \\
\hline $\mathrm{T}_{\text {on }}$ & 0.94 & 1 & 0.94 & 759.15 & $<0.0001^{*}$ \\
\hline $\mathrm{T}_{\text {off }}$ & 5.19 & 1 & 5.19 & 4182.12 & $<0.0001^{*}$ \\
\hline $\mathrm{P}_{\mathrm{c}}$ & 0.55 & 1 & 0.55 & 440.68 & $<0.0001^{*}$ \\
\hline $\mathrm{I}_{\mathrm{p}} \mathrm{T}_{\text {on }}$ & 0.14 & 1 & 0.14 & 110.70 & $<0.0001^{*}$ \\
\hline $\mathrm{I}_{\mathrm{p}} \mathrm{T}_{\text {off }}$ & 0.61 & 1 & 0.61 & 489.66 & $<0.0001^{*}$ \\
\hline $\mathrm{I}_{\mathrm{p}} \mathrm{P}_{\mathrm{c}}$ & 0.37 & 1 & 0.37 & 301.65 & $<0.0001^{*}$ \\
\hline $\mathrm{T}_{\text {on }} \mathrm{T}_{\text {off }}$ & $2.078 \mathrm{E}-04$ & 1 & $2.078 \mathrm{E}-04$ & 0.17 & 0.6881 \\
\hline $\mathrm{T}_{\text {on }} \mathrm{P}_{\mathrm{c}}$ & 0.077 & 1 & 0.077 & 62.41 & $<0.0001^{*}$ \\
\hline $\mathrm{T}_{\text {off }} \mathrm{P}_{\mathrm{c}}$ & 0.50 & 1 & 0.50 & 406.99 & $<0.0001^{*}$ \\
\hline $\mathrm{I}_{\mathrm{p}}^{2}$ & 0.12 & 1 & 0.12 & 93.53 & $<.0001^{*}$ \\
\hline $\mathrm{T}_{\text {on }}{ }^{2}$ & 0.011 & 1 & 0.011 & 8.48 & $0.0107 *$ \\
\hline $\mathrm{T}_{\text {off }}^{2}$ & $8.004 \mathrm{E}-03$ & 1 & $8.004 \mathrm{E}-03$ & 6.45 & $0.0226^{*}$ \\
\hline$\overline{\mathrm{P}_{\mathrm{c}}{ }^{2}}$ & 8.683E-03 & 1 & 8.683E-03 & 7.00 & $0.0184 *$ \\
\hline Residual & 0.019 & 15 & $1.241 \mathrm{E}-03$ & & \\
\hline $\begin{array}{l}\text { Lack of } \\
\text { Fit }\end{array}$ & 0.010 & 10 & $1.031 \mathrm{E}-03$ & 0.62 & $0.7562 * *$ \\
\hline Pure error & 8.298E-03 & 5 & $1.660 \mathrm{E}-03$ & & \\
\hline Cor Total & 11.14 & 29 & & & \\
\hline \multicolumn{2}{|l|}{ R-Squared } & & & & 0.9983 \\
\hline \multicolumn{2}{|c|}{ Adj R-Squared } & & & & 0.9968 \\
\hline \multicolumn{2}{|c|}{ Pred R-Squared } & & & & 0.9936 \\
\hline \multicolumn{2}{|c|}{ Adeq Precision } & & & & 109.946 \\
\hline
\end{tabular}

Table 6. ANOVA for Response SR

SS: sum of squares, df: degree of freedom, MS: mean squares,

$(*)$ : significant, $(* *)$ : not significant

Variation of actual and predicted values using Eq. (4) are plotted in Figure 3 and residuals V/s normal plots for $\mathrm{SF}$ are shown in Figure 4. Comparison of predicted value of SR with actual values SR indicates very good agreement, ANOVA and analysis of a normal plot of residuals for SF also confirms the adequacy and prediction capability of the model.

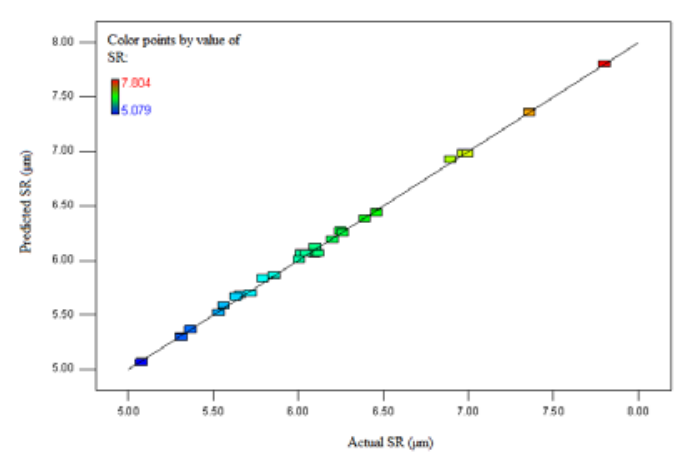

Figure 3. Variation actual and predicted response for SR

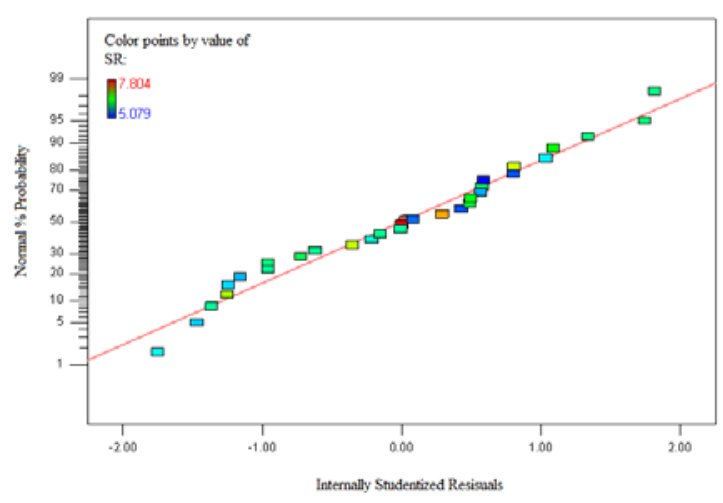

Figure 4. Plot of residuals for SR

\section{Validation of Developed Model}

Additional confirmation experiments were carried out to validate the models developed for the performance responses SDR and SR. New data sets were used within the range of the input process parameters (i.e., $\mathrm{I}_{\mathrm{p}}, \mathrm{T}_{\text {on }}, \mathrm{T}_{\text {off }}$, $\mathrm{P}_{\mathrm{c}}$ ), and these were different from data sets already used for formulating the models. Baraskar et al. [13] developed the concept of prediction error percentage to compare the predicted values and the actual confirmation experimental values to validate the results.

The average prediction error percentage for SDR and SR model was found to be $7.8 \%$ and $5.7 \%$ subsequently. These are reasonably good for the confirmation of the developed models. This confirms the adequacy of models developed for SDR and SR by RSM.

\section{Conclusions}

Based on the experimental investigations the models for SDR and SR were developed for peak current, pulse-on time, pulse-off time and electrode compaction pressure. The following conclusions have been drawn within the range of the process parameters selected:

- The mathematical model for surface deposition rate (SDR) developed is:

$$
\begin{aligned}
\mathrm{SDR}= & +33.88+5.30 \mathrm{I}_{\mathrm{p}}+0.79 \mathrm{~T}_{\text {on }}-8.43 \mathrm{~T}_{\text {off }} \\
& -1.34 \mathrm{P}_{\mathrm{C}}-1.08 \mathrm{I}_{\mathrm{p}} \mathrm{T}_{\text {off }}-1.63 \mathrm{I}_{\mathrm{p}}{ }^{2}-1.01 \mathrm{~T}_{\text {on }}{ }^{2}-1.41 \mathrm{P}_{\mathrm{C}}{ }^{2}
\end{aligned}
$$

- The average prediction error of SDR model is 7.8\%. 
- The second order polynomial mathematical model obtained by using response surface methodology for SR is:

$$
\begin{aligned}
\mathrm{SR}= & +6.06-0.33 \mathrm{I}_{\mathrm{p}}+0.20 \mathrm{~T}_{\text {on }}-0.46 \mathrm{~T}_{\text {off }}-0.15 \mathrm{P}_{\mathrm{c}} \\
& -0.093 \mathrm{I}_{\mathrm{p}} \mathrm{T}_{\text {on }}+0.19 \mathrm{I}_{\mathrm{p}} \mathrm{T}_{\text {off }}+0.15 \mathrm{I}_{\mathrm{p}} \mathrm{P}_{\mathrm{c}}+0.070 \mathrm{~T}_{\text {on }} \mathrm{P}_{\mathrm{c}} \\
& +0.18 \mathrm{~T}_{\text {off }} \mathrm{P}_{\mathrm{c}}+0.065 \mathrm{I}_{\mathrm{p}}{ }^{2}-0.020 \mathrm{~T}_{\text {on }}{ }^{2}-0.017 \mathrm{~T}_{\text {off }}{ }^{2} \\
& +0.018 \mathrm{P}_{\mathrm{C}}^{2}
\end{aligned}
$$

- In case of SR mathematical model, the average prediction error comes out to be 5.7\%.

- The values of average prediction errors of these models reveal the adequacy of the developed models.

\section{References}

[1] Ho, K.H. and Newman, S.T, "State of the art electrical discharge machining (EDM)," International Journal of Machine Tools and Manufacture, 43, 1287-1300, June 2003.

[2] Singh, S., Maheshwari, S. and Pandey, P.C, "Some investigations in to the electrical discharge machining of hardened tool steel using different electrode materials," J Mater Process Technol, 149, 272-277, Nov 2004.

[3] Barash, M.M. and Kahlon, C.S, "Experiments with electric spark toughening, International Journal of Machine Tool Design \& Research, 4, 1-8, June 1964.

[4] Venkatesh, V.C. and Parasnis, S, "Surface transformation in high speed steel after electro discharge machining," Proceedings of the 5th AIMTDR Conference, IIT Rookee, India, 639-649, 1972.
[5] Koshy, G., Philip, P.K. and Geddam, A, "Hardening of surface layers using electric discharge techniques." Proceedings of the11th AIMTDR Conference, IIT, Madras, 315-319, 1983.

[6] Furutani, K., Saneto, A., Takezawa, Y., Mohri, N. and Miyke, H, "Accretion of titanium carbide by electrical discharge machining with powder suspended in working fluid," Journal of International Societies for Precision Engineering, 25, 138-144, March 2001.

[7] Bing, H. Y., Chung, T. H. and Yuan, H. F, "The effect in EDM of a dielectric of a urea solution in water on modifying the surface of titanium," International Journal of Machine Tools and manufacture, 45, 194-200, July 2005.

[8] Sharif, S. and Noordin, R.M, "Machinability modeling in powder mixed dielectric EDM of titanium alloy Ti6246," Proceeding of the first international conference and seventh AUN/SEED-net Fieldwise Seminar on Manufacturing and Material Processing, Kuala Lumpur, 133-138. March 2006.

[9] Kansal, H.K., Singh, S. and Kumar, P, "Parametric optimization of powder mixed electrical discharge machining by response surface methodology," J Mater Process Technol, 169, 427-436, March 2005.

[10] Sony, J.S. and Chakraverti, G, "Experimental investigations on migration of material during EDM of T215 Cr12 die steel," Journal of materials Processing Technology, 56, 439-451, January 1996.

[11] Mohri, N., Saito, N. and Tsunekawa, Y, "Metal surface modification by electrical discharge machining with composite electrode," Ann CIRP 42, (1), 219-222, 1993.

[12] Montgomery, D.C, Design and Analysis of Experiments, John Wiley and Sons, New York, 2001.

[13] Baraskar, S.S., Banwait, S.S. and Laroiya, S.C, "Multi-objective optimization of electrical discharge machining process using Derringer’s desirability,” Int. J. Materials Engineering Innovation, 2, 203-221, October 2011. 